Www.jmscr.igmpublication.org

Impact Factor (SJIF): 6.379

Index Copernicus Value: 71.58

ISSN (e)-2347-176x ISSN (p) 2455-0450

crossrefDOI: https://dx.doi.org/10.18535/jmscr/v6i7.197

Journal Of Medical Science And Clinical Research

\title{
Clinical Profile of Patients with Cortical venous Thrombosis: A Hospital Based Study
}

\author{
Authors \\ Dr Ajay Khanna ${ }^{1}$, Dr Nandani ${ }^{2}$, Dr Nipendra Kishore ${ }^{3}$, Dr Abhay Kumar \\ ${ }^{1}$ Associate Professor, Department of Medicine, Subharti Medical College, Dehradun, Uttarakhand, India \\ ${ }^{2}$ Consultant, Department of Biochemistry, S.K. Memorial, Hospital, Dehradun, Uttarakhand, India \\ ${ }^{3}$ Senior Resident, Department of Orthopaedics, Katihar Medical College, Katihar, Bihar, India \\ ${ }^{4}$ Associate Professor, Department of Surgery, Government Doon Medical College and Hospital, Dehradun, \\ Uttarakhand, India \\ Corresponding Author \\ Dr Nandani \\ Consultant, Department of Biochemistry, S. K. Memorial, Hospital, Dehradun, Uttarakhand, India \\ Ph: +91 9410102582, Email: drnandani123@gmail.com
}

\begin{abstract}
Aims: Aim of our study was to evaluate the clinical profile of patients with cortical venous thrombosis. Methods: A detail history, clinical examination and relevant investigations were performed to all cases. Laboratory investigations like complete blood count with peripheral smear, ESR, RBS, serum urea, serum creatinine, LFT, serum electrolytes, urine routine, ECG in all leads, CSF analysis(whenever necessary), prothrombin time, activated partial thromboplastin time, CT scan, MRI and MR venogram were performed to all patients with cerebral venous thrombosis.

Results: Data was analyzed with the help of MS- office software.

Conclusions: Young age female patients were more prone to cortical venous thrombosis. Headache, convulsion and altered sensorium, hemiparesis, pallor, papilloedema were common initial symptoms and sign. Transverse sinus, sigmoid sinus and superior sagital sinus were commonly involved. Mortality rate was higher in patients with severe anaemia, haemmorhagic CVT and two or more than two sinus involvement of patients with cortical venous thrombosis.

Keywords: Cortical venous thrombosis, clinical profile, investigative profile, MR venogram.
\end{abstract}

\section{Introduction}

Cerebral venous sinus thrombosis (CVST) is an uncommon condition which over the past 5 to 10 years has been diagnosed more frequently due to greater awareness and the availability of better non-invasive diagnostic techniques. Because of the generally good prognosis and variable clinical signs, many cases remain clinically undetected.
CVST is slightly more common in women, particularly in the age group of 20 to 35 , due to pregnancy, puerperium and oral contraceptive use. ${ }^{[1]}$

In the late 1970's, hospital-based series from Northern India documented CVT in a frequency of 4.5/1000 obstetric admissions. ${ }^{[2]}$ Another population-based study from Southern India in the 
late 1960 's found that $25 \%$ of stroke patients were less than $(<) 40$ years of age and were primarily young women having a CVT that had occurred in the postpartum stage. ${ }^{[3]}$

Incidence of CVT may be more in India compared to the western countries. This was probably due to the reporting of many large series of puerperal CVT from India in the 70's and 80's. ${ }^{[4]}$ But, due to the lack of any population-based study or nationwide multicentric hospital-based studies, the exact incidence of CVT in India is still not known. There have been a few epidemiological studies from the western countries trying to determine the incidence of CVT. In a nationwide hospital-based series in Portugal, an incidence of 0.22/100,000 /year has been reported. ${ }^{[5]} \mathrm{A}$ well-designed crosssectional epidemiological study performed in the Netherlands had shown an incidence of 1.32/100,000/year. ${ }^{[6]}$

MRI combined with MRV is reliable as the sole examination for the Condition of cerebral venous thrombosis. ${ }^{[7,8]}$ It can show the consequences of thrombosis such as cerebral oedema, infarction and haemorrhage as well as the anatomy of the disturbed venous circulation.

Intravenous heparin should be the first-line treatment, even in the presence of haemorrhagic infarction, provided there are no general contraindications to its use. ${ }^{[9,10]}$ If the patient deteriorates despite adequate heparinisation or presents moribund with coma, selective catheterguided local thrombolysis may be an option, ${ }^{[9,10]}$ in spite of the increased haemorrhagic risk. This should be followed by 3-6 months of oral anticoagulation. Aim of our study was to evaluate the clinical and investigative profile of patients with cortical venous thrombosis.

\section{Material and Methods}

A total of 40 patients (19:males and 21:females) with age group 15 to $>60$ years of cortical venous thrombosis were selected in this study. Attendents/patients signed an informed consent approved by institutional ethical committee of Subharti Medical College and Hospital, Dehradun,
Uttrakhand, India was sought. Data was collected in the indoor and outpatients department, in department of Medicine, Subharti Medical College. Dehradun, Uttrakhand during a period from February 2016 to December 2016.

Inclusion Criteria: Patients age > 15 years and those with confirmed diagnosis (based on neuroimaging) of cerebral venous sinus thrombosis were included in this study.

Cases with hypertensive haemorrhage, atherothrombotic stroke and metabolic encephalopathies were excluded in this study.

Methods: Detail assessment was taken to all cases of cortical venous thrombosis. History, clinical examination and relevant investigation were performed. MR venogram was peroformed to confirm the patients of cerebral venous thrombosis.

Investigations: A relevant laboratory investigations were performed to all cases like complete blood count with peripheral smear, ESR, RBS, serum urea, serum creatinine, LFT, serum electrolytes, urine routine, ECG in all leads, CSF analysis(whenever necessary), prothrombin time, activated partial thromboplastin time, CT scan, MRI and MR venogram.

\section{Statistical Analysis}

Data was analyzed by using the simple statistical methods with the help of MS-Office software.

\section{Observation}

This study was conducted in department of Medicine, Subharti Medical College, Dehradun, Utrakhand.

In this study, we were included a total of 40 cases of cortical venous thrombosis with age group of 15 to > 60 years. Majority of cases $15(37.5 \%)$ were in age group of 15-30 years. 10(25\%) were in age group of 31-45 years. $8(20 \%)$ cases were in age group of $>60$ years. And $7(17.5 \%)$ cases were in age group of 46-60 years. 19(47.5\%) males and $21(52.5 \%)$ females were included in this study. 
Table 1. Showing the aetiology of patients with CVT out of 40 cases.

\begin{tabular}{|l|c|}
\hline Aetiology & Condition \\
\hline Puerperal & $11(47.82 \%)$ \\
\hline Infective & $5(21.73 \%)$ \\
\hline Traumatic & $5(21.73 \%)$ \\
\hline Hyperhemocysteinaemic & $2(8.69 \%)$ \\
\hline Total & $23(57.5 \%)$ \\
\hline
\end{tabular}

In this study, out of 40 cases of CVT, 23 cases of aetiological factors were $11(47.82 \%)$ puerperal, $5(21.73 \%)$ infective, $5(21.73 \%)$ traumatic and $2(8.69 \%)$ hyperhemocysteinaemia. And rest cases 17(42.5\%) were unknown aetiology.

Table 2. Showing the type of cortical venous thrombosis.

\begin{tabular}{|l|c|c|}
\hline Type of CVT & No. of patients & Percentage \\
\hline Puerperal & 11 & $27.5 \%$ \\
\hline Non-puerperal & 29 & $72.5 \%$ \\
\hline Total & 40 & $100 \%$ \\
\hline
\end{tabular}

In this study, 11 (27.5\%) puerperal and 29(72.5\%) non-puerperal cases of cortical venous thrombosis were found.

Table 3. showing the type of CVT in female patients

\begin{tabular}{|l|c|c|}
\hline Type of CVT in female & No. of patients & Percentage \\
\hline Puerperal & 9 & $42.85 \%$ \\
\hline Non puerperal & 12 & $57.14 \%$ \\
\hline Total & 21 & $100 \%$ \\
\hline
\end{tabular}

In this present study, out of 21 female cases of CVT, 9(42.85\%) puerperal and 12(57.14\%) nonpuerperal were found.

Table 4. Showing the duration from delivery till onset of symptoms.

\begin{tabular}{|l|c|c|}
\hline Duration (Days) & No. of patients & Percentage \\
\hline $1-10$ & 5 & $55.56 \%$ \\
\hline $11-20$ & 2 & $22.22 \%$ \\
\hline $21-30$ & 0 & $0 \%$ \\
\hline$>30$ & 2 & $22.22 \%$ \\
\hline
\end{tabular}

In this study. Out of 9 cases of puerperal, (55.56\%) 5 majority of cases of CVT was duration till onset of symptoms after delivery 1 to 10 days.

Table 5. Mode of onset of symptoms of patients with CVT.

\begin{tabular}{|l|c|c|}
\hline Onset & No. of patients & Percentage \\
\hline Acute & 18 & $45 \%$ \\
\hline Sub acute & 20 & $50 \%$ \\
\hline Chronic & 2 & $5 \%$ \\
\hline Total & 40 & $100 \%$ \\
\hline
\end{tabular}

Out of 40 cases of CVT, 20(50\%) subacute, $18(45 \%)$ acute and 2(5\%) chronic were seen.

Table 6. Showing the level of consciousness of patients with cortical venous thrombosis (CVT).

\begin{tabular}{|l|c|c|}
\hline $\begin{array}{l}\text { Level of } \\
\text { consciousness }\end{array}$ & No. of patients & Percentage \\
\hline Consciousness & 13 & $32.5 \%$ \\
\hline Drowsy & 8 & $20 \%$ \\
\hline Stuporous & 11 & $27.5 \%$ \\
\hline Comatose & 8 & $20 \%$ \\
\hline Total & 40 & $100 \%$ \\
\hline
\end{tabular}

In this present study, out of 40 cases of CVT, level of consciousness was 13(32.5\%) consciousness, 8 (20\%) drowsy, 11(27.5\%) stuporous and $8(20 \%)$ comatose.

Table 7. Showing the initial symptom of presentation of presentation of patients with CVT.

\begin{tabular}{|l|c|c|}
\hline $\begin{array}{l}\text { Initial symptoms of } \\
\text { presentation }\end{array}$ & No. of patients & Percentage \\
\hline Headache & 20 & $50 \%$ \\
\hline Convulsions & 20 & $50 \%$ \\
\hline Focal deficit & 12 & $30 \%$ \\
\hline Altered sensorium & 21 & $52.5 \%$ \\
\hline Vomiting & 11 & $27.5 \%$ \\
\hline Fever & 9 & $22.5 \%$ \\
\hline
\end{tabular}

Initial clinical symptoms of presentation of patients with CVT was 20(50\%) headache, $20(50 \%)$ convulsion, $12(30 \%)$ focal deficit, $21(52.5 \%)$ altered sensorium, 11(27.5\%) vomiting and $9(22.5 \%)$ fever followed to each other.

Table.8. Showing the clinical sign of presentation of patients with CVT.

\begin{tabular}{|l|c|c|}
\hline Sign & No. of patients & Percentage \\
\hline Hemiparesis & 12 & $30 \%$ \\
\hline Papilloedema & 10 & $25 \%$ \\
\hline Pallor nerve & 22 & $55 \%$ \\
\hline $\begin{array}{l}\text { Cranial } \\
\text { involvement }\end{array}$ & 5 & $12.5 \%$ \\
\hline
\end{tabular}

Clinical sign of cases of CVT were 12(30\%) hemiparesis, $10(25 \%)$ papiloloedema, 22(55\%) pallor and $5(12.5 \%)$ cranial nerve involvement followed to each other. 
Table 9. Showing the investigations of patients with CVT

\begin{tabular}{|c|c|c|c|}
\hline $\begin{array}{l}\mathrm{Hb} \quad(\mathrm{gm} \\
\%)\end{array}$ & $\begin{array}{c}\text { No. of patients } \\
\text { alive }\end{array}$ & $\begin{array}{c}\text { No. of patients } \\
\text { dead }\end{array}$ & $\begin{array}{l}\text { No. of } \\
\text { cases }\end{array}$ \\
\hline$<5$ & $4(66.67 \%)$ & $2(33.33 \%)$ & 6 \\
\hline $5-8$ & $7(87.5 \%)$ & $1((12.5 \%)$ & 8 \\
\hline $8-10$ & $10(83.33 \%)$ & $2(16.67 \%)$ & 12 \\
\hline$>10$ & $14(100 \%)$ & 0 & 14 \\
\hline Total & $35(87.5 \%)$ & $5(12.5 \%)$ & 40 \\
\hline
\end{tabular}

In this present study, were seen that cases who had $\mathrm{Hb}$ level less than $5 \mathrm{gm} \%$, 4(66.67\%) cases were alive and $2(33.33 \%)$ cases were dead. That was seen that mortality rate was higher with greater degree of severity of anaemia.

Table 10. Showing the sinus involvement of patients with CVT.

In this present study, cases of CVT were sinus involvement associated to each other, 21(52.5\%) superior sagital sinus, 25(62.5\%) transverse sinus, $23(57.5 \%)$ sigmoid sinus, $5(12.5 \%)$ jugular sinus, $7(17.5 \%)$ straight sinus and $13(32.5 \%)$ internal cerebral vein. Transcverse sinus was more involved in cases of CVT.

Table 11 Showing the CSF analysis of patients with CVT.

\begin{tabular}{|l|c|c|}
\hline CSF & No. of patients & Percentage \\
\hline Normal & 9 & $37.5 \%$ \\
\hline Pleocytosis & 5 & $20.83 \%$ \\
\hline Protein rise & 10 & $41.66 \%$ \\
\hline
\end{tabular}

Out of 40 cases, CSF examination was done in 24 cases of CVT. 9(37.5\%) cases were normal CSF findings, $5(20.83 \%)$ pleocytosis and $10(41.66 \%)$ protein rise.

Table 12. Showing the MRI findings of patients with CVT.

\begin{tabular}{|l|l|l|}
\hline MRI & No. of patients & Percentage \\
\hline Haemorrhagic & 25 & $62.5 \%$ \\
\hline Non haemorrhagic & 7 & $17.5 \%$ \\
\hline
\end{tabular}

\begin{tabular}{|l|c|c|}
\hline Sinus involvement & No. of patients & Percentage \\
\hline Superior sagital sinus & 21 & $52.5 \%$ \\
\hline Transverse sinus & 25 & $62.5 \%$ \\
\hline Sigmoid sinus & 23 & $57.5 \%$ \\
\hline Jugular sinus & 5 & $12.5 \%$ \\
\hline Straight sinus & 7 & $17.5 \%$ \\
\hline Internal cerebral vein & 13 & $32.5 \%$ \\
\hline
\end{tabular}

Out of 40 cases, MRI was performed in 32 cases of CVT. Haemorrhage was seen in 25(62.5\%) cases.

Table 13. Showing the Mortality rate of patients with CVT.

\begin{tabular}{|l|c|c|}
\hline Status & No. of patients & Percentage \\
\hline Alive & 34 & $85 \%$ \\
\hline Dead & 6 & $15 \%$ \\
\hline
\end{tabular}

In this present study, we were found that majority of cases $34(85 \%)$ were alive.

Table.14. Showing the mortality in hemorrhagic infarct and non hemorrhagic infarct of patients with CVT.

\begin{tabular}{|l|c|c|}
\hline & HI & NHI \\
\hline Alive & $21(84 \%)$ & $5(71.42 \%)$ \\
\hline Mortality & $4(16 \%)$ & $2(28.57 \%)$ \\
\hline Total & 25 & 7 \\
\hline
\end{tabular}

In this present study, out of 25 cases of haemorrhagic infarct, mortality rate was $4(16 \%)$ and in non haemorrhagic infarct, out 7 cases mortality rate was $2(28.57 \%)$.

Table 15 Showing the number of sinus involvement of patients with CVT.

\begin{tabular}{|l|c|c|}
\hline & Mortality & Percentage \\
\hline 1 & 1 & $16.67 \%$ \\
\hline 2 or more than 2 & 5 & $83.33 \%$ \\
\hline
\end{tabular}

In this present study, mortality was greater 5 $(83.33 \%)$ of cases who had two and more than two sinus involvement.

Table 16. Treatment of patients with cortical venous thrombosis.

\begin{tabular}{|l|l|l|l|}
\hline Conditions & $\begin{array}{l}\text { No. of } \\
\text { patients }\end{array}$ & Recovered & Death \\
\hline Age >30 years & 25 & 21 & 4 \\
\hline Duration < 10 days & 30 & 26 & 4 \\
\hline Altered sensorium & 21 & 17 & 4 \\
\hline Convulsions & 20 & 18 & 2 \\
\hline Fever & 9 & 8 & 1 \\
\hline Focal deficit & 12 & 10 & 2 \\
\hline Puerperium & 9 & 9 & 0 \\
\hline Haemorrhagic infarct & 25 & 22 & 3 \\
\hline Non haemorrhagic infarct & 7 & 5 & 2 \\
\hline SSS involvement & 20 & 17 & 3 \\
\hline Single sinus involvement & 10 & 9 & 1 \\
\hline $\begin{array}{l}\text { Two or more } \\
\text { involvement }\end{array}$ & 27 & 23 & 4 \\
\hline Transeverse sinus involvement & 25 & 21 & 4 \\
\hline Sigmoid sinus involvement & 23 & 19 & 4 \\
\hline
\end{tabular}


In this present study, after treatment of the patients, mortality rate was higher of patients with age $>30$ years, duration $<10$ days, altered sensorium, haemorrhagic infarct, SSS involvement, two or more sinus involvement, transverse sinus involvement and sigmoid sinus involvement.

\section{Discussion}

Cerebral venous-sinus thrombosis (CVST) is a potential life-threatening condition that requires rapid diagnosis and urgent treatment. Its epidemiology has changed over past few decades. ${ }^{[11]}$ Its increasing prevalence may be attributed to not only increased ease of diagnosis by modern imaging tools such as magnetic resonance imaging (MRI), but also to the increment of underlying causes including use of oral contraceptive pills (OCPs). ${ }^{[1,12]}$ Cerebral venoussinus thrombosis seems relatively more frequent in South Asia and Middle East. ${ }^{[11]}$

In this present study, we were included a total of 40 cases of cortical venous thrombosis with age group of 15 to $>60$ years. Higher incidence 15 $(37.5 \%)$ of cortical venous thrombosis was seen in young age group patients (15-30 years) patients. Females 21(52.5\%) were more affected with cerebral venous thrombosis than males 19(47.5\%). Similar finding was found by Hernando Raphael Alvis-Miranda. et al (2013). ${ }^{[13]}$ They were studied on patients with cerebral venous thrombosis and stated that cerebral sinus venous thrombosis (CSVT) is a rare phenomenon that seen with some frequency in young patients. Nahid Ashjazadeh, et al. (2011) were said that cerebral venous-sinus thrombosis is an uncommon form but important cause of stroke, especially in youngaged women. ${ }^{[14]}$

In this present study, out of 40 cases of CVT, 23 cases $(57.5 \%)$ of aetiological factors were $11(47.82 \%)$ puerperal, $5(21.73 \%)$ infective, $5(21.73 \%)$ traumatic and $2(8.69 \%)$ hyperhemocysteinaemia. And rest cases $17(42.5 \%)$ were unknown aetiology. In this present study, out of 21 female cases of CVT, 9(42.85\%) puerperal.
Out of 9 cases of puerperal, 5(55.56\%) majority of cases were 1-10 days for onset of symptoms after delivery of child.

CSVT is characterized by a highly variable clinical spectra, difficult diagnosis, variable etiologies and prognosis. Of interest, in poor countries, there is an association with the puerperium, with no clear arguments, but probably related to factors such as inappropriate perinatal care, metabolic derangements, and infections associated to childbirth. ${ }^{[15]}$ The peripartum-associated CSVT has been established to be of 11.6 cases per 100000 deliveries. ${ }^{[16]}$ There is sex predominance (hormonal?); $75 \%$ of all CSVT patients are women, with a 3:1 ratio compared to men. ${ }^{[17]}$ The IJV represent the main outflow pathway for the cerebral venous system. ${ }^{[18]}$ IJV abnormalities may change the hemodynamics of cerebral venous outflow, leading to insufficient venous drainage, and subsequently causing CSVT. In a study performed by Jia et al., ${ }^{[19]}$ found that among 51 consecutive CSVT cases with unknown etiologies, $61 \%$ of the cases (31/51) had an IJV abnormality; furthermore, almost all the CSVT occurred on the same side as the IJV lesions, which strongly suggests a close association between IJV abnormalities and CSVT. However, a predisposing factor may not be identified in up to $20-35 \%$ of cases. ${ }^{[20,21]}$

In present study, out of 40 cases of CVT, 20(50\%) subacute, $18(45 \%)$ acute and $2(5 \%)$ chronic were seen. A study conducted by Guenther G, et al. ${ }^{[15]}$ and they were concluded that in $30 \%$ of CSVT cases, it presents in an acute fashion and the symptoms appear in less than $48 \mathrm{~h}$. In up to $50 \%$ of cases, it presents in a sub-acute fashion and the symptoms appear between $48 \mathrm{~h}$ and 30 days. The chronic form corresponds to $20 \%$ of cases, and the symptoms develop over a period greater than 30 days and up to 6 months.

In our study, level of consciousness was $13(32.5 \%)$ consciousness, $8(20 \%)$ drowsy, $11(27.5 \%)$ stuporous and $8(20 \%)$ comatose. Initial clinical symptoms of presentation of patients was 
$20(50 \%)$ headache, $20(50 \%)$ convulsion, $12(30 \%)$ focal deficit, 21(52.5\%) altered sensorium, $11(27.5 \%)$ vomiting and $9(22.5 \%)$ fever followed to each other. Clinical sign of cases of CVT were $12(30 \%)$ hemiparesis, $10(25 \%)$ papiloloedema, $22(55 \%)$ pallor and $5(12.5 \%)$ cranial nerve involvement followed to each other.

In this present study, 21(52.5\%) superior sagital sinus, $25(62.5 \%)$ transverse sinus, 23(57.5\%) sigmoid sinus, $5(12.5 \%)$ jugular sinus, $7(17.5 \%)$ straight sinus and $13(32.5 \%)$ internal cerebral vein were involved in cases of cortical venous thrombosis. Involvement of sinuses was followed to other sinuses.

CVST presents with a wide spectrum of symptoms and signs. Headache is the presenting symptom in $70-90 \%$ of cases. ${ }^{[20,21,22]}$ Focal deficits such as hemiparesis and hemisensory disturbance, seizures, impairment of level of consciousness and papilloedema occur in onethird to three-quarters of cases. ${ }^{[20,22]}$ The onset may be acute, subacute or insidious, most patients presenting with symptoms which have evolved over days or weeks. ${ }^{[20]}$ There are several typical clinical constellations ${ }^{[21,23]}$ : $18-38 \%$ of cases present with a syndrome resembling benign intracranial hypertension with headache, papilloedema and visual disturbances; up to $75 \%$ of cases are characterised by a focal neurological deficit andheadache; a third group of between $30 \%$ and $50 \%$ may present with seizures often followed by a Todd's paresis. Rare but classical clinical pictures are that of superior sagital sinus thrombosis $(4 \%)$ with bilateral or alternating deficits and/or seizures and cavernous sinus thrombosis $(3 \%)$ with chemosis, proptosis and painful ophthalmoplegia. ${ }^{[20]}$ An even less frequent presentation is a rapidly progressive illness with deepening coma, headache, nausea and pyramidal signs, due to extensive involvement of the deep cerebral veins. ${ }^{[24]}$

In this present study, we were seen that mortality rate $2(33.33 \%)$ was higher in degree of severity of anaemia. The other investigative procedures like leucocyte count, blood sugar, serum creatinine, blood urea, liver function tests and serum electrolytes were not contributed to the diagnosis and were nonspecific.

In present study, out of 40 cases, CSF examinations was performed in 24 cases, majority of cases $10(42.66 \%)$ had rise of protein in CSF, pleocytosis $5(20.83 \%)$ and normal CSF findings $9(37.5 \%)$.

In this present study, MRI was performed in 32 cases of CVT. 25(62.5\%) cases were haemorrhagic infarct and 7(17.5\%) nonhaemorrhagic. Out of 25 cases of haemorrhagic infarct, mortality rate was $4(16 \%)$ and in out of 7 cases of non haemorrhagic infarct, mortality rate was $2(28.57 \%)$. All the 40 cases of cortical venous thrombosis were treated with anticoagulants. All patients were subjected to LMWH and then switched on to warfarin therapy maintaining the INR value 1.5 to 2 times normal. Patients were followed at 15 days interval and values of INR reviewed. Patients of hyperhomocysteinaemia were given folic acid and vitamin B12.

The different routes of administration reflect uncertainty of opinions among neurologists as to what type of heparin to be used. In the part, CVST had been associated with a dismal prognosis and high mortality rate, reaching $30-50 \%$. The recent ISCVT study performed in the era of modern neuroimaging, LHWH administration and endovascular intervention reported much lower mortality rates $(8-14 \%)$ and significantly better outcome.

Out of 40 cases of cerebral venous thrombosis in our study, majority of cases $34(85 \%)$ were alive and mortality rate was $6(15 \%)$. Mortality rate was higher of patients with age>30 years, duration < 10 days, altered sensorium, haemorrhagic infarct, SSS involvement, two or more sinus involvement, transverse sinus involvement and sigmoid sinus involvement followed to each other.

According to Villringer A, et al. ${ }^{[21]}$ and de Bruijn SF, et al. ${ }^{[25]}$ between 57 and $86 \%$ of patients have complete functional recovery. Mortality rates was between $5.5 \%$ and $18 \% .{ }^{[21,25]}$ Even though there appears to be no clear correlation between disease 
severity and outcome, ${ }^{[20]}$ several factors are associated with a poorer prognosis. These are, most importantly, ${ }^{[26]}$ infancy and advanced age, rapid onset with coma and focal deficits, and thrombosis affecting largely the deep venous system. The underlying condition, particularly sepsis, malignancy, and paroxysmal nocturnal haemoglobinuria adversely affect outcome. ${ }^{[26]}$ Seizures rarely occur beyond the acute stages. ${ }^{[27]}$

\section{Conclusion}

Our study concluded that the young age female patients were more prone to cortical venous thrombosis. Headache, convulsion and altered sensorium, hemiparesis, pallor, papilloedema were common initial symptoms and sign of patients with cortical venous thrombosis. Transverse sinus, sigmoid sinus and superior sagital sinus were commonly involved. Mortality rate was higher in patients with severe anaemia, haemmorhagic CVT and two or more than two sinus involvement of patients with cortical venous thrombosis.

\section{References}

1. Holger Allroggen, Richard $\mathrm{J}$ Abbott. Cerebral venous sinus thrombosis. Postgrad Med J 2000;76:12-15.

2. Bansal BC, Gupta RR, Prakash C. Stroke during pregnancy and puerperium in young females below the age of 40 years as a result of cerebral venous/venous sinus thrombosis. Jpn Heart J 1980;21:171-73.

3. Abraham J, Rao PS, Inbaraj SG, Shetty G, Jose CJ. An epidemiological study of hemiplegia due to stroke in South India. Stroke 1970;1:477-81.

4. Nagaraja D, Taly AB, Das S: Puerperal cerebral venous thrombosis in India. In: Progress in Clinical Neurosciences. Sinha KK, Chandra P. (Eds), NSI Publication. Ranchi 1989; 165-177.

5. Ferro JM, Correia M, Pontes C, Baptista MV, Pita F, Cerebral Venous Thrombosis Portuguese Collaborative Study Group (Venoport). Cerebral vein and dural sinus thrombosis in Portugal: 1980-1998. Cerebrovasc Dis 2001;11:177-82.

6. Coutinho JM, Zuurbier SM, Aramideh M, Stam J. The incidence of cerebral venous thrombosis: A cross-sectional study. Stroke 2012;43:3375-7.

7. Wang, AM. MRA of venous sinus thrombosis. Clin Neurosci 1997;4:158-64.

8. Villringer A, Einhäupl KM. Dural sinus and cerebral venous thrombosis. New Horizons 1997;5:332-41.

9. Bousser MG. Cerebral venous thrombosis: nothing, heparin, or local thrombolysis? Stroke 1999;30:481-3.

10. Siddiqui FM, Kamal AK. Incidence and epidemiology of cerebral venous thrombosis. J Pak Med Assoc 2006; 56: 485-7.

11. Saadatnia M, Tajmirriahi M. Hormonal contraceptives as a risk factor for cerebral venous and sinus thrombosis. Acta Neurol Scand 2007; 115: 295-300.

12. Hernando Raphael Alvis-Miranda, Sandra Milena Castellar-Leones, Gabriel AlcalaCerra, andLuis Rafael Moscote-Salazar. Cerebral sinus venous thrombosis. J Neurosci Rural Pract. 2013 Oct-Dec; 4(4): 427-438.

13. Nahid Ashjazadeh, Afshin Borhani Haghighi, Maryam Poursadeghfard, Hoseinjan Azin. Cerebral Venous-Sinus Thrombosis: A Case Series Analysis. Iran J Med Sci September 2011; 36: 3179.

14. Guenther G, Arauz A. Cerebral venous thrombosis: A diagnostic and treatment update. Neurologia.2011;26:488-98.

15. Lanska DJ, Kryscio RJ. Risk factors for peripartum and postpartum stroke and intracranial venous thrombosis.Stroke. 2000;31:1274-82.

16. Ferro JM, Canhão P, Stam J, Bousser MG, Barinagarrementeria F. Prognosis of cerebral vein and dural sinus thrombosis: Results of the International Study on Cerebral Vein and Dural Sinus 
Thrombosis (ISCVT) Stroke.2004;35:66470.

17. Menegatti E, Zamboni P. Doppler haemodynamics of cerebral venous return. Curr Neurovasc Res.2008;5:260-5.

18. Jia LY, Hua Y, Ji XM, Liu JT. Correlation analysis of internal jugular vein abnormalities and cerebral venous sinus thrombosis. Chin Med J (Engl) 2012;125: 3671-4.

19. Diakou M, Kostadima V, Giannopoulos S, Zikou AK, Argyropoulou MI, Kyritsis AP. Cerebral venous thrombosis in an adolescent with ulcerative colitis. Brain Dev. 2011;33:49-51.

20. Ameri A, Bousser MG. Cerebral venous thrombosis. Neurol Clin 1992;10:87-111.

21. Villringer A, Mehraen S, Einhäupl KM. Pathophysiological aspects of cerebral sinus venous thrombosis. J Neuroradiol 1994;21:72-80.

22. Bousser MG, Chiras J, Bories J, Castagne P. Cerebral venous thrombosis - a review of 38 cases. Stroke 1985;16:199-213.

23. Bousser MG, Barnett HJM. Cerebral venous thrombosis. In: Stroke: pathophysiology, diagnosis and management, 2nd edn. New York: Churchill- Livingstone, 1992; pp 517-37.

24. Crawford SC, Digre KB, Palmer CA, et al. Thrombosis of the deep venous drainage of the brain in adults. Analysis of 7 cases with review of the literature. Arch Neurol 1995;52:1101-8.

25. de Bruijn SF, Stam J, for the CVST Study Group. Randomised, placebo-controlled trial of anticoagulant treatment with lowmolecularweight heparin for cerebral sinus thrombosis. Stroke 1999;30:484-8.

26. Bousser MG, Russell RR. Cerebral venous thrombosis. London:W B Saunders, 1997.
27. Preter M, Tzourio C, Ameri A, Bousser MG. Long-term prognosis in cerebral venous thrombosis: follow-up of 77 patients. Stroke 1996;27:243-6. 